\title{
Liver-specific HBsAg transgenic mice are over-sensitive to Poly(I:C)-induced liver injury in NK cell- and IFN- $\gamma$-dependent manner ${ }^{\text {is }}$
}

\author{
Yongyan Chen, Rui Sun*, Wei Jiang, Haiming Wei, Zhigang Tian* \\ Institute of Immunology, Hefei National Laboratory for Physical Sciences at Microscale, School of Life Sciences, \\ University of Science and Technology of China, 443 Huangshan Road, Hefei City, Anhui 230027, PR China
}

Background/Aims: The role of natural killer (NK) cells in the development of hepatitis B virus (HBV)-associated liver injury remains obscure. In this study, we elucidated the role of NK cells in liver injury of HBsAg transgenic mice (HBsB6), a mimic of human healthy chronic HBsAg carriers, triggered by polyinosinic:polycytidylic acid [Poly(I:C)].

Methods: HBs-B6 or wild B6 mice were intraperitoneally injected with Poly(I:C) at different doses. Liver injury was evaluated by serum transaminase activity and histopathologic changes.

Results: HBs-B6 mice were over-sensitive to Poly(I:C)-induced liver injury, which was absolutely dependent on the presence of NK cells and IFN- $\gamma$ produced by intrahepatic NK cells. Much stronger IFN- $\gamma$ receptor expression was observed on hepatocytes of HBs-B6 mice, which was significantly enhanced by Poly(I:C) injection. Treatment with IFN- $\gamma$ in vitro triggered much higher activation of downstream signals (pSTAT1-IRF-1) in hepatocytes of HBs-B6 mice. Depletion of Kupffer cells and neutralization of endogenous IL-12 did not affect Poly(I:C)-induced over-sensitive liver injury in HBs-B6 mice.

Conclusions: NK cells played a critical role in an IFN- $\gamma$ dependent, Kupffer cell- and IL-12-independent manner in oversensitive liver injury triggered by Poly(I:C) in murine chronic HBsAg carriers.

(C) 2007 European Association for the Study of the Liver. Published by Elsevier B.V. All rights reserved.

Keywords: Hepatitis B virus; Liver injury; Natural killer cell; IFN- $\gamma$; Polyinosinic:polycytidylic acid

\section{Introduction}

Hepatitis B virus (HBV) primarily infects hepatocytes and causes a series of liver diseases such as acute and chronic hepatitis, liver cirrhosis and hepatocellular carcinoma, which are among the most important human health problems worldwide [1-3]. It has been reported that the immune responses are fundamental for viral clearance and pathogenesis during HBV infection; however, the precise mechanisms of innate immune responses

Received 7 December 2006; received in revised form 12 February 2007; accepted 22 February 2007; available online 19 March 2007

is The authors declare that they do not have anything to disclose regarding funding or conflict of interest with respect to this manuscript.

* Corresponding authors.

E-mail addresses: sunr@ustc.edu.cn (R. Sun), tzg@ustc.edu.cn (Z. Tian). responsible for the autoimmune-associated liver injury are poorly defined [3]. Liver is a lymphoid organ with an overwhelming innate immune system [4-7]. Natural killer (NK) cells are abundant in the normal liver, accounting for around one-third of intrahepatic lymphocytes [4,5]. Available evidence has indicated that hepatic NK cells play an important anti-viral role during HBV infection, but the role in the development of HBV-associated liver injury remains obscure [8].

Due to the limited host range of HBV and difficulties in getting human liver samples, autoimmune liver injury models and HBV transgenic mouse models were applied to investigate the role of NK cells in liver injury. Activated hepatic NK cells are able to kill hepatocytes and induce liver injury such as viral liver infection (adenovirus), Pseudomonas aeruginosa exotoxin A (PEA) injection and carrageenan administration [9-11], and polyinosinic:polycytidylic acid [Poly(I:C)] injection as reported by Makoto Ochi et al. and us [12,13]. Mole- 
cules including IFN- $\gamma$, IL-12, Perforin and TRAIL contributed to NK cell cytotoxicity against hepatocytes [9,11-13]. Furthermore, pre-activated $\mathrm{T}$ cells by a low dose of ConA could enhance the ability of Poly(I:C)activated NK cells to cause more severe hepatocyte injury [14]. However, activated NK cells in some cases are not involved in liver injury, as reported in ConAinduced hepatitis or $\alpha$-GalCer-induced liver injury [1517]. In HBV transgenic mice, activated NK cells caused liver injury when inhibiting HBV replication [18-22]. However, Guidotti et al. demonstrated that activated NK cells contributed to viral clearance without any cytopathic effects on liver in the HBV-infected chimpanzee [23]. So the precise role of NK cells in the liver injury during HBV infection deserves further investigation.

It is extensively recognized that ten percent of adults and $90 \%$ of children become persistent virus carriers after HBV infection. In this study, hepatitis B surface antigen $(\mathrm{HBs} \mathrm{Ag})$ transgenic mice, which mimic human healthy chronic HBsAg carriers [24,25], were triggered by a synthetic dsRNA analogue Poly(I:C), a ligand of toll-like receptor 3 (TLR3) and also a well-known potent activator for NK cells $[13,14,26]$. In our previous study, injection of Poly(I:C) could preferentially recruit and activate NK cells in liver and induce mild liver injury in wild mice $[13,14]$. Here, we further demonstrated that the HBsAg transgenic mice were over-sensitive to Poly(I:C)-induced liver injury, which was absolutely dependent on hepatic NK cells. NK cells played their critical role in an IFN- $\gamma$ dependent and Kupffer cell- and IL-12-independent manner in these HBsAg transgenic mice, which was completely different from wild mice as we previously observed [13].

\section{Materials and methods}

\subsection{Mice}

HBsAg transgenic mice C57BL/6J-TgN (AlblHBV) 44Bri (named as HBs-B6 mice in this study) were used, which express HBsAg in serum, liver and kidney tissues to mimic human healthy chronic HBsAg carriers [24,25]. Eight- to 10-week-old male HBs-B6 mice were obtained from VITALRIVER Experiment Animal Company (Beijing) which purchased them from Jackson Lab and bred them for us. Their littermates C57BL/6J mice (B6 mice) were also obtained as control. Al mice were maintained under specific-pathogen-free conditions with human care. Experimental procedures were conducted in accordance with experimental animal's guidelines.

\subsection{Reagents}

Poly(I:C) (Sigma Chemical Co., St Louis, MO) was dissolved in the pyrogen-free phosphate-buffered saline (PBS) at the concentration of $1 \mathrm{mg} / \mathrm{ml}$ and intraperitoneally injected to mice at indicated doses. The mAbs for flow cytometry analysis included FITC-conjugated anti-NK1.1, PE-conjugated anti-IFN- $\gamma$, PE-CY5-conjugated antiCD3e, Biotin-anti-CD119 (IFN- $\gamma \mathrm{R} \alpha$ chain) (BD PharMingen, San Diego), FITC-conjugated streptavidin (eBioscience, San Diego). Recombinant mIFN- $\gamma$ (Pepro Tech INC) was dissolved in pyrogen- free PBS at the concentration of $25 \mu \mathrm{g} / \mathrm{ml}$, and was intravenously injected to mice at a series of doses to observe its effect on liver injury. For in vitro experiments, cultured hepatocytes were treated with recombinant $\mathrm{mIFN}-\gamma(2 \mathrm{ng} / \mathrm{ml})$ or PBS. Anti-phospho-STAT1 (Tyr701) and anti-IRF-1 antibodies were purchased from Cell Signaling Technology (Beverly, MA). Anti-actin antibody was obtained from Boster (Wuhan, China). Horseradish peroxidase-conjugated secondary Abs was obtained from Promega (Beijing, China).

\subsection{Assay for serum transaminase activity}

Serum samples from individual mice were obtained at indicated time points. Serum alanine aminotransferase (ALT) and aspartate aminotransferase (AST) activities were determined using commercial available kit (Rong Sheng, Shanghai, China) and calculated from the standard curve.

\section{4. $H-E$ staining}

Liver tissues were fixed in $10 \%$ neutral buffered formalin at least for $24 \mathrm{~h}$ and then embedded in paraffin. Five-micron sections were affixed to slides, deparaffinized, and stained with hematoxylin and eosin to determine morphologic changes.

\subsection{Cell depletion}

A dose of $50 \mu \mathrm{l}$ anti-ASGM1 antibody with the concentration of $1 \mathrm{mg} / \mathrm{ml}$ (Wako Pure Chemical Industries Ltd., Osaka, Japan) or same amount of control rabbit IgG (Sino-American Biotechnology Co., Beijing, China) was intravenously injected into mice $24 \mathrm{~h}$ before the following treatment to deplete NK cells [14]. To deplete Kupffer cells in vivo, gadolinium chloride $\left(\mathrm{GdCl}_{3}\right)$ (Sigma Chemical Co., St. Louis, MO) was intravenously injected at $10 \mathrm{mg} / \mathrm{kg}$ body weight $24 \mathrm{~h}$ before the following treatment $[27,28]$. These protocols resulted in a $\geqslant 90 \%$ decrease in the number of the indicated cells, which was confirmed by flow cytometry.

\subsection{Cytokine neutralization}

Anti-IFN- $\gamma$ neutralizing mAb (R4-6A2, IgG $_{1}$ ) and anti-interleukin

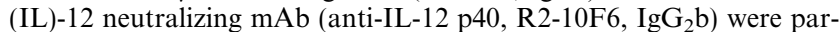
tially purified from hybridoma culture supernatant by ammonium sulfate precipitation obtained from American Type Culture Collection (Manassas, VA, USA). Mice were given three injections of the indicated $\mathrm{mAb}(50 \mu \mathrm{g}$ per mouse) intraperitoneally on three consecutive days before the following treatment to neutralize the cytokine in vivo. Control rat IgG (Sino-American Biotechnology Co.) was injected at equivalent doses and schedules.

\subsection{Isolation and culture of primary mouse hepatocytes}

The isolation and culture of primary mouse hepatocytes were performed as described [29]. Followed by treatment with IFN- $\gamma$ for various time periods, downstream signals of hepatocytes were determined by Western blotting.

\subsection{Flow cytometry analysis}

Hepatic mononuclear cells (MNCs) were prepared as described previously [24]. For the intracellular cytokine assay, MNCs were cultured in the presence of $30 \mathrm{ng} / \mathrm{ml}$ PMA, $1 \mu \mathrm{g} / \mathrm{ml}$ ionomycin (Calbiochem, Darmstadt, Germany) and $6 \mu \mathrm{M}$ monensin (Sigma Chemical Co., St. Louis, MO) for $4 \mathrm{~h}$ in humidified $5 \% \mathrm{CO}_{2}$ at $37^{\circ} \mathrm{C}$. After blocking with anti-FcR, MNCs were stained in darkness at $4{ }^{\circ} \mathrm{C}$ for 30 min with the indicated mAbs FITC-conjugated anti-NK1.1 and PE-CY5-conjugated anti-CD3e for the surface antigens. Subsequently, cells were fixed and permeabilized using $100 \mu \mathrm{l}$ of cytofix and cytoperm solution (eBioscience, San Diego, CA, USA), respectively, and then 
stained with PE-conjugated anti-IFN- $\gamma \mathrm{mAb}$. For IFN- $\gamma$ receptor assay, after blocking with anti-FcR isolated hepatocytes were stained with Biotin-anti-CD119 in darkness at $4{ }^{\circ} \mathrm{C}$ for $30 \mathrm{~min}$, and then washed three times before being stained with FITC-conjugated streptavidin in darkness at $4{ }^{\circ} \mathrm{C}$ for $30 \mathrm{~min}$. Stained cells were washed three times and then examined by FACScalibur (Becton-Dickinson) and analyzed with WinMDI 2.8 software.

\subsection{Western blotting}

Cells were lysed in cell lysis buffer for western and IP (Beyotime, China) added with $1 \mathrm{mM}$ PMSF for $30 \mathrm{~min}$ in ice, and then centrifuged at $12,000 \mathrm{~g}$ for $15 \mathrm{~min}$ at $4{ }^{\circ} \mathrm{C}$. The supernatants were mixed in Laemmli loading buffer, boiled for $5 \mathrm{~min}$, and then subjected to SDSPAGE. After electrophoresis, proteins were transferred onto PVDF membranes (Millipore Corporation, Billerica, USA), and blotted against primary Abs overnight at $4{ }^{\circ} \mathrm{C}$. Membranes were washed with $0.1 \%(\mathrm{vol} / \mathrm{vol})$ Tween $20 \mathrm{in} \mathrm{TBS} \mathrm{(pH} \mathrm{7.6)} \mathrm{and} \mathrm{incubated} \mathrm{with} \mathrm{a} \mathrm{1:2500}$ dilution of horseradish peroxidase-conjugated secondary Abs for $60 \mathrm{~min}$ at room temperature. Protein bands were visualized by ECL reaction (Pierce)

\subsection{Statistical analysis}

Differences between the groups were analyzed by Student's $t$ test and $P<0.05$ was considered statistically significant.

\section{Results}

\subsection{HBs-B6 mice were over-sensitive to Poly (I: C)-induced liver injury}

As previously reported by us [13], Poly(I:C)-induced mild liver injury in wild B6 mice at a high dose of $20 \mu \mathrm{g} / \mathrm{g}$ body weight. However, a lower dose of Poly(I:C) $(7.5 \mu \mathrm{g} / \mathrm{g}$ body weight) could induce remarkable elevation of ALT in HBs-B6 mice. As shown in Fig. 1, Poly(I:C) injection induced much higher elevations of serum ALT and AST in HBs-B6 mice than wild B6 mice, even with a much low dose $(3 \mu \mathrm{g} / \mathrm{g}$ body weight). Furthermore, there was no significant difference in the peak level of serum ALT between a low dose of Poly(I:C) $(3 \mu \mathrm{g} / \mathrm{g}$ body weight $)$ - and a high dose of Poly(I:C) $(30 \mu \mathrm{g} / \mathrm{g}$ body weight $)$ - treated HBs-B6 mice. In wild B6 mice, there were only slight elevations of serum ALT and AST after $30 \mu \mathrm{g} / \mathrm{g}$ body weight Poly(I:C) injection. Liver histology further confirmed that injection of low dose of Poly(I:C) $(3 \mu \mathrm{g} / \mathrm{g}$ body weight) induced severe hepatocyte necrosis and inflammation in HBs-B6 mice, but no morphologic changes in the liver of wild B6 mice (Fig. 2). These results demonstrated that HBs-B6 mice were over-sensitive to Poly(I:C)-induced liver injury.

\subsection{NK cells played a critical role in the over-sensitive liver injury in $\mathrm{HBs}-\mathrm{B} 6$ mice after $\operatorname{Poly}(\mathrm{I}: \mathrm{C})$ injection}

NK cells were preferentially accumulated and activated in the liver after $\operatorname{Poly}(\mathrm{I}: \mathrm{C})$ injection both in wild B6 mice and HBs-B6 mice [13,24]. We previously
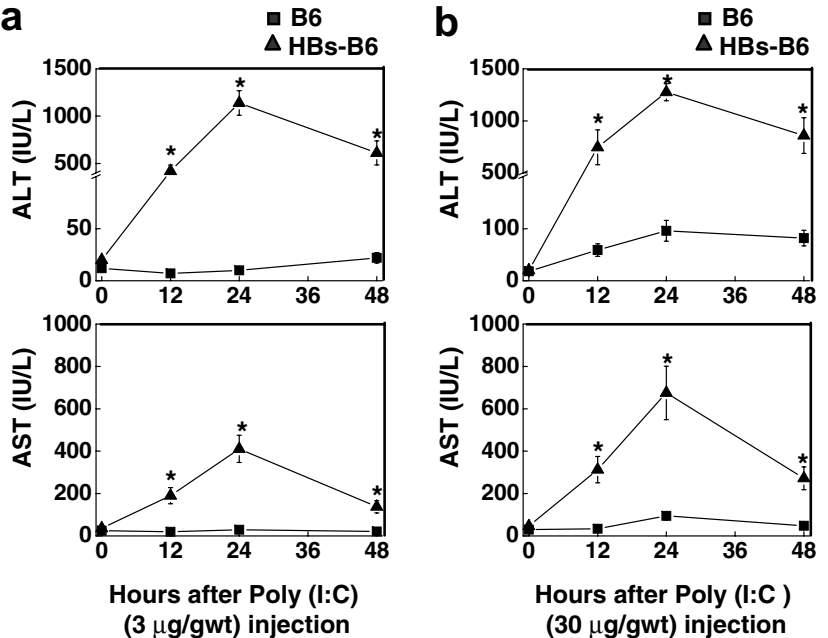

Fig. 1. Serum ALT/AST in HBs-B6 mice after Poly(I:C) injection. Poly(I:C) was injected intraperitoneally to $\mathrm{HBs}-\mathrm{B} 6$ mice and wild B6 mice with different doses. Serum ALT and AST levels were measured at 0, 12, 24 and $48 \mathrm{~h}$ after Poly(I:C) injection. (a) Levels of serum ALT/ AST after $3 \mu \mathrm{g} / \mathrm{g}$ body weight Poly(I:C) injection. (b) Levels of serum ALT/AST after $30 \mu \mathrm{g} / \mathrm{g}$ body weight $\operatorname{Poly}(\mathrm{I}: \mathrm{C})$ injection. Values are shown as means \pm SEM from five mice at each time point in each group. ${ }^{*} P<0.05$ vs. $B 6$ mice.

reported that Poly(I:C)-activated NK cells were implicated in the mild liver injury in wild B6 mice [13]. In order to directly elucidate the role of NK cells in the over-sensitive liver injury induced by low dose of Poly(I:C) in HBs-B6 mice, depletion of NK cells was achieved by pretreatment with anti-ASGM1 antibody. As shown in Fig. 3, depletion of NK cells significantly decreased levels of serum ALT and AST by effectively
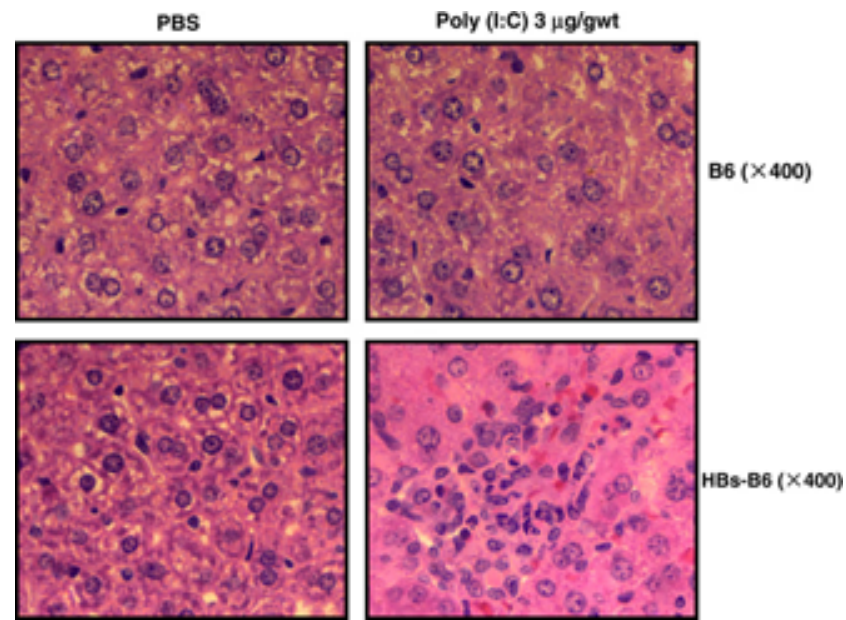

Fig. 2. Severe hepatocyte necrosis and inflammation in HBs-B6 mice after low dose of Poly(I:C) injection. Twenty-four hours after $3 \mu \mathrm{g} / \mathrm{g}$ body weight Poly(I:C) or PBS injection, liver samples were collected from HBs-B6 and wild B6 mice, and then liver sections were prepared and stained with hematoxylin and eosin (original magnification $400 \times$ ). These were from a single experiment representative of three independent experiments. [This figure appears in colour on the web.] 

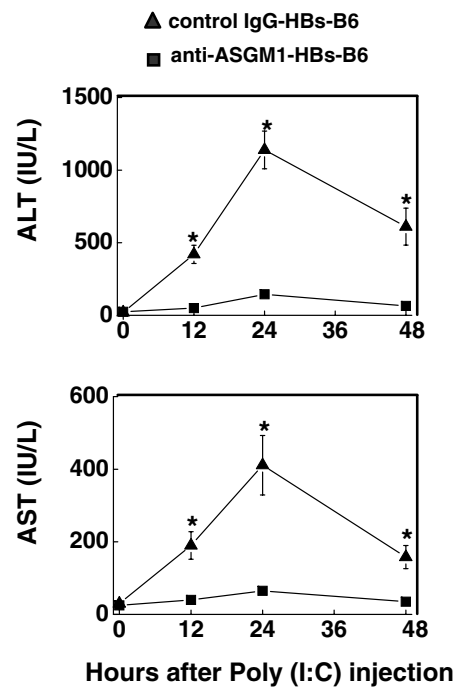

Fig. 3. Depletion of NK cells attenuated liver injury induced by low dose of Poly(I:C) in HBs-B6 mice. HBs-B6 mice were treated with control rabbit IgG or anti-ASGM1 antibody for $24 \mathrm{~h}$, followed by injection of Poly(I:C) (3 $\mu \mathrm{g} / \mathrm{g}$ body weight). At $0,12,24$ and $48 \mathrm{~h}$ after Poly(I:C) injection, serum ALT and AST levels were measured. Values are shown as means \pm SEM from four mice at each time point in each group. ${ }^{*} \boldsymbol{P}<0.05$ vs. corresponding control group.

abrogating low dose of Poly(I:C)-induced liver injury in HBs-B6 mice, suggesting that the over-sensitivity to Poly(I:C)-induced liver injury of HBs-B6 mice was dependent on NK cells.

\subsection{NK cell-mediated liver injury was dependent on IFN- $\gamma$} in HBs-B6 mice after Poly (I:C) injection

After low dose of Poly(I:C) injection, largely enhanced IFN- $\gamma$ production by intrahepatic NK cells was observed in both HBs-B6 mice and wild B6 mice (Fig. 4a). However, neutralization of endogenous IFN$\gamma$ by pretreatment with anti-IFN- $\gamma$ mAb absolutely alleviated the liver injury induced by low dose of Poly(I:C) in HBs-B6 mice (Fig. 4b), indicating that IFN- $\gamma$ played a crucial role in over-sensitive liver injury of HBs-B6 mice. Further, HBs-B6 or wild B6 mice were injected with different doses of recombinant $\operatorname{mIFN}-\gamma$, and the results demonstrated that a dose of $7.5 \mu \mathrm{g}$ recombinant mIFN- $\gamma$ could induce marked liver injury in HBs-B6 mice, but not in wild B6 mice (Fig. 4c), indicating that HBs-B6 mice were hypersensitive to IFN- $\gamma$ in liver injury.

As shown in Fig. 5a, the expression of IFN- $\gamma$ receptor on hepatocytes of HBs-B6 mice was much stronger than that of wild B6 mice (12.89\% vs. 1.00\%); Poly(I:C) injection significantly enhanced the expression of IFN- $\gamma$ receptor on hepatocytes of HBs-B6 mice, but not on hepatocytes of wild B6 mice. Further, the higher activation of downstream signals pSTAT1-IRF-1 in hepatocytes of HBs-B6 mice after treatment with IFN- $\gamma$ in vitro was observed (Fig. 5b).
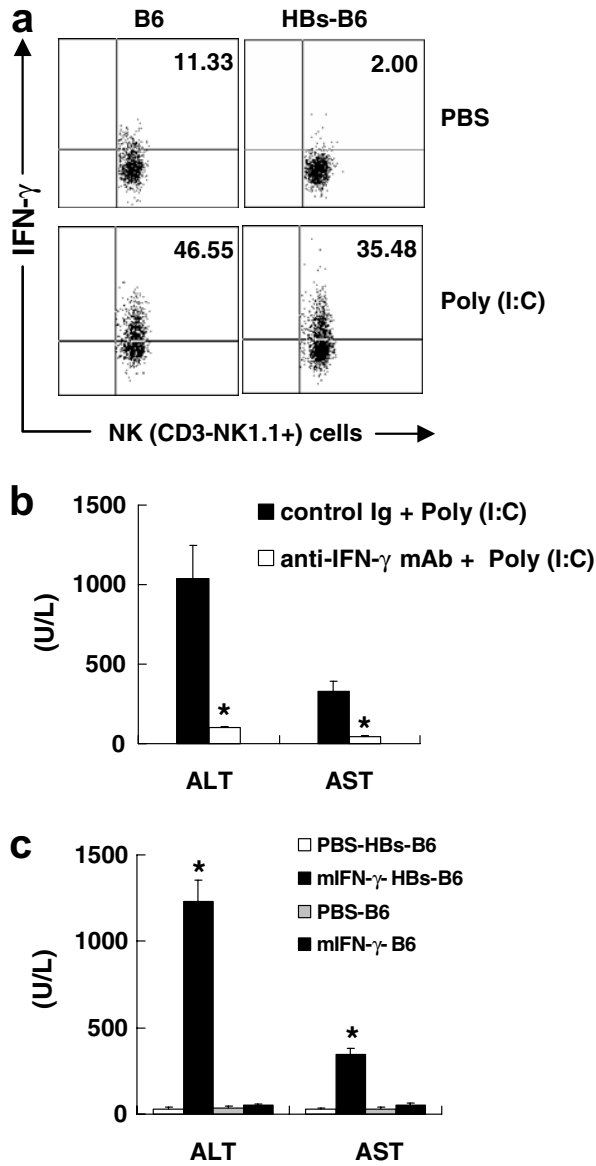

Fig. 4. NK cell-mediated liver injury was dependent on IFN- $\gamma$ in HBs-B6 mice after low dose of Poly(I:C) injection. (a) Twenty-four hours after Poly(I:C) (3 $\mu \mathrm{g} / \mathrm{g}$ body weight) or PBS injection, liver MNCs were prepared and then analyzed by flow cytometry for intracellular IFN- $\gamma$ of NK cells. A representative example of three independent experiments is shown. (b) HBs-B6 mice were treated with anti-IFN- $\gamma$ mAb to neutralize endogenous IFN- $\gamma$ before Poly(I:C) $(3 \mu \mathrm{g} / \mathrm{g}$ body weight) injection. Serum ALT and AST were determined $24 \mathrm{~h}$ after Poly(I:C) injection. Data are shown as means \pm SEM from four mice in each group. ${ }^{*} P<0.05$ as comparison with the control. (c) A dose of $7.5 \mu \mathrm{g}$ recombinant mIFN- $\gamma$ or PBS was injected iv. to HBs-B6 and wild B6 mice. At $24 \mathrm{~h}$ after IFN- $\gamma$ injection, serum ALT and AST levels were determined. Data are shown as means \pm SEM from four mice in each group. ${ }^{*} P<0.05$ vs. corresponding control group.

\subsection{NK cell-mediated liver injury was Kupffer cell- and IL-12-independent in $\mathrm{HBs}$-B6 mice after Poly $(\mathrm{I}: \mathrm{C})$ injection}

We previously reported that Kupffer cell-produced IL-12 played critical roles in Poly(I:C)-induced NK cell accumulation and the subsequent mild liver injury in wild B6 mice [13]. However, as shown by the levels of serum ALT and AST in Fig. 6, depletion of Kupffer cells by pretreatment of $\mathrm{GdCl}_{3}$ did not change the Poly(I:C)induced liver injury in HBs-B6 mice; and neutralization of endogenous IL-12 by pretreatment with anti-IL-12 $\mathrm{mAb}$ neither affected the liver injury. These results 
a

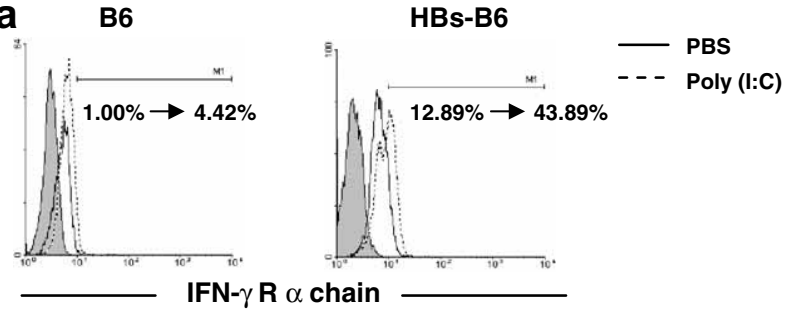

Fig. 5. Stronger expression of IFN- $\gamma$ receptor and higher IFN- $\gamma$ activated downstream signals pSTAT-1-IRF-1 in hepatocytes of HBs-B6 mice. (a) Six hours after Poly(I:C) $(3 \mu \mathrm{g} / \mathrm{g}$ body weight) or PBS injection, hepatocytes of HBs-B6 and wild B6 mice were prepared and then analyzed for IFN- $\gamma \mathrm{R} \alpha$ chain by flow cytometry. A representative example of three independent experiments is shown. The gray histogram is for the negative control in each group. (b) Western blotting analyses of pSTAT-1 and IRF-1 from primary HBs-B6 and wild B6 mouse hepatocytes treated with IFN- $\gamma(2 \mathrm{ng} / \mathrm{ml})$ in vitro for $0,0.5,1$ and $3 \mathrm{~h}$, respectively.

indicated that Kupffer cells and IL-12 were not necessary for NK cells to mediate the Poly(I:C)-triggered liver injury in HBs-B6 mice.
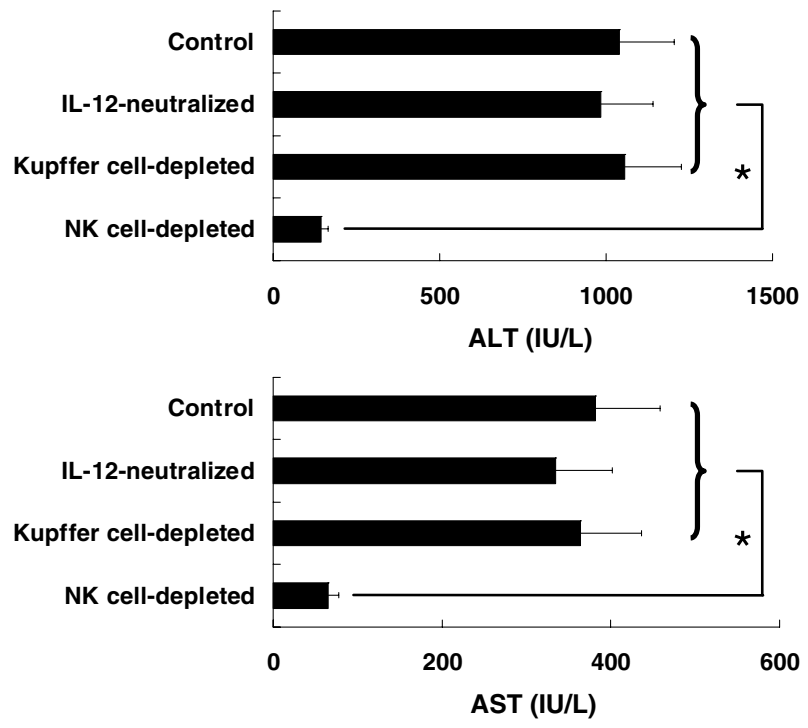

Fig. 6. NK cell mediated-liver injury was Kupffer cell- and IL-12independent in HBs-B6 mice after low dose of $\operatorname{Poly}(\mathrm{I}: \mathrm{C})$ injection. Depletion of NK cells was achieved by pretreatment with anti-ASGM1 antibody and depletion of Kupffer cells was achieved by pretreatment with $\mathrm{GdCl}_{3} 24 \mathrm{~h}$ before Poly(I:C) injection in HBs-B6 mice. Endogenous IL-12 was neutralized by pretreatment with anti-IL-12 mAb on three consecutive days before Poly(I:C) injection in HBs-B6 mice. Serum ALT and AST were determined $24 \mathrm{~h}$ after Poly(I:C) $(3 \mu \mathrm{g} / \mathrm{g}$ body weight) injection. Values are shown as means \pm SEM from four mice in each group. ${ }^{*} P<0.05$ vs. Kupffer cell-depleted or IL-12-neutralized or control.

\section{Discussion}

In this study, we demonstrate that Poly(I:C) triggers over-sensitive liver injury of murine chronic HBsAg carriers in an NK cell-dependent manner. We have previously reported that Poly(I:C)-induced mild liver injury was dependent on NK cells, and Kupffer cells played critical roles in Poly(I:C)-induced NK cell accumulation and the subsequent liver injury in wild mice [13]. However, in current HBsAg transgenic mice Poly(I:C)induced liver injury is independent of Kupffer cells (Fig. 6). After Poly(I:C) injection, more NK cells were accumulated in the liver and persisted longer in $\mathrm{HBsAg}$ transgenic mice [24], of which the actual molecular mechanisms remained unclear. So, it seems that mechanisms of NK cell activation by Poly(I:C) are different in Kupffer cell-dependence in HBsAg transgenic mice and wild mice. In addition, we reported that NKT cells were not involved in Poly(I:C)-induced NK cell-mediated liver injury [13], which was further confirmed by us in $\mathrm{HBsAg}$ transgenic mice by comparison of NKT/NK cell depletion by anti-NK1.1 mAb with NK cell depletion by anti-ASGM-1 antibody since lack of $\mathrm{HBsAg}^{+} \mathrm{CD}^{-1-}$ mice (data not shown), indicating that the over-sensitive liver injury was mainly dependent on NK cells. Interestingly, NK cells did not contribute to $\alpha$-GalCer-induced NKT cell-mediated hepatocyte injury in wild mice [17], but injection of $\alpha$-GalCer into HBsAg transgenic mice induced more severe NKT cell-mediated liver injury, which was dependent on NK cells [30]. So, taken together, NK cells play the critical role in over-sensitive liver injury of $\mathrm{HBsAg}$ transgenic mice after triggering with Poly(I:C) or $\alpha$-GalCer although the dependence on NKT cells is absolutely different.

As a self-antigen, HBsAg could not usually induce specific immune responses to $\mathrm{HBsAg}$ in the immunologically tolerant transgenic mice. As previously reported [31-33], structure of virus such as mouse cytomegalovirus (MCMV) m157 may be recognized as the ligand of activating or inhibitory NK cell receptor (so called "none-self"), by which NK cells may attack self-tissue. Until now, no report including our preliminary study (data not shown) demonstrates that HBsAg has the character. Also, virus proteins such as MCMV m155-, m145-, m152- or m138-encoded glycoprotein may induce the virus infected cells to down-express or upexpress the ligands of activating NK cell receptor (so called "induced-self" or "missing-self", respectively), by which NK cells may attack self-tissue too [34-38]. We practiced the experiments to explore the ligands of activating $\mathrm{NK}$ cell receptor on hepatocytes of $\mathrm{HBsAg}$ transgenic mice, and no significant change was found (data not shown). On the other hand, after Poly(I:C) injection, NK cells were preferentially accumulated and activated in the liver $[13,24]$ and produced large amount of IFN- $\gamma$ similarly (Fig. 4a) in both $\mathrm{HBsAg}$ 
transgenic mice and wild B6 mice. As previously reported by us [13], IFN- $\gamma$ were not responsible for Poly(I:C)-induced mild liver injury in wild mice, although IFN- $\gamma$ has been considered to play a critical role in liver injury induced by other immunostimulants [39-41]. However, in the present study, IFN- $\gamma$ was involved in Poly(I:C)-induced over-sensitive liver injury in HBsAg transgenic mice after verifying by IFN- $\gamma$ neutralization and rmIFN- $\gamma$ injection (Fig. 4). Gilles et al. reported that $\mathrm{HBs} \mathrm{Ag}$-positive hepatocytes are extraordinarily sensitive to the cytolytic effect of IFN- $\gamma$ in vivo [42], but the IFN- $\gamma$-producing cells as well as effector cells were not delineated in their study. Here, we demonstrated that NK cells were the effectors to mediate the over-sensitive liver injury in an IFN- $\gamma$-dependent manner in HBsAg transgenic mice. As demonstrated in ConA-induced hepatitis or LPS/D-galactosamineinduced liver damage, IFN- $\gamma$ plays an important role in the development of hepatic inflammation and liver injury through induction of chemokines, adhesive molecules, and proapoptotic proteins by activation of STAT1 [29,43-46]. We observed higher expressions of IFN- $\gamma$ receptor on hepatocytes of $\mathrm{HBsAg}$ transgenic mice and stronger IFN- $\gamma$ signaling of pSTAT1-IRF-1, which might account for the hypersensitivity to IFN- $\gamma$ induced hepatocyte injury in HBsAg transgenic mice (Fig. 5).

TNF- $\alpha$ is another important inflammatory cytokine in liver injury $[41,47,48]$, but does not contribute to Poly(I:C)-induced liver injury in wild mice [13]. In HBsAg transgenic mice, HBsAg-positive hepatocytes were not hypersensitive to the cytolytic effect of TNF$\alpha$ [42]. Since neutralization of IFN- $\gamma$ completely inhibited the over-sensitive liver injury induced by Poly(I:C) in this study, it was speculated that TNF- $\alpha$ was not necessary to the over-sensitive liver injury in HBsAg transgenic mice. Poly( $\mathrm{I}: \mathrm{C})$ can stimulate the production of IL-12, which then promotes NK cell accumulation in the liver $[49,50]$. In Poly(I:C)-induced liver injury of wild mice, Kupffer cell-derived IL-12 played critical roles in NK cell function [13]. IL-12 has been shown to exacerbate ConA-induced hepatitis in wild mice [51]. However, in this study, the Poly(I:C)-induced over-sensitive liver injury in $\mathrm{HBsAg}$ transgenic mice was independent of IL-12. We still do not know why NK cell-derived IFN- $\gamma$ is strong enough to induce liver injury in $\mathrm{HBsAg}$ transgenic mice, regardless of the presence of IL-12 (Fig. 6).

It has been known that human healthy HBsAg carriers are susceptible to hepatocyte injury, as a serious risk for development of liver cirrhosis and hepatocellular carcinoma [52], however, the pathogenesis has not been well understood. During HBV infection, a variety of elements such as stresses, infections, pregnancy and use or withdrawal of immunosuppressive therapies are disadvantageous to induce hepatocyte injury [53]. In the present study, by using HBsAg transgenic mice that mimic human chronic HBsAg carriers, we used Poly(I:C), as a mimicking exoteric stimulant of virus infection $[13,14,26]$, to investigate the underlying innate immune mechanisms of hepatocyte injury during HBV infection. Our study elucidated for the first time that activated NK cells were responsible for the over-sensitivity to hepatocyte injury of chronic HBsAg carriers in an IFN- $\gamma$-dependent manner.

\section{Acknowledgments}

This work was supported by Natural Science Foundation of China (\#30630059, \#30528007, \#30570819, \#30571695,), Ministry of Science \& Technology of China (973 Basic Science Project 2006CB806504, 2006CB504300, \#2003CB515501) and Ministry of Education of PR China (\#705029).

\section{References}

[1] Seeger C, Mason WS. Hepatitis B virus biology. Microbiol Mol Biol Rev 2000;64:51-58.

[2] Rehermann B, Nascimbeni M. Immunology of hepatitis B virus and hepatitis C virus infection. Nat Rev Immunol 2005;5:215-229.

[3] Christina M, Page JGR. Immunology of hepatitis B infection. Lancet Infect Dis 2001;2:43-50.

[4] Mackay IR. Hepatoimmunity: a perspective. Immunol Cell Biol 2002;80:36-44.

[5] Norris S, Collins C, Doherty DG, Smith F, McEntee G, Traynor $\mathrm{O}$, et al. Resident human hepatic lymphocytes are phenotypically different from circulating lymphocytes. J Hepatol 1998;28:84-90.

[6] Mehal WZ, Azzaroli F, Crispe IN. Immunology of the healthy liver: old questions and new insights. Gastroenterology 2001;120:250-260.

[7] Kita H, Mackay IR, Van de Water J, Gershwin ME. The lymphoid liver: considerations on pathways to autoimmune injury. Gastroenterology 2001;120:1485-1501.

[8] Chen Y, Wei H, Gao B, Hu Z, Zheng S, Tian Z. Activation and function of hepatic NK cells in hepatitis B infection: an under investigated innate immune response. J Viral Hepat. 2005;1:34-38.

[9] Liu ZX, Govindarajan S, Okamoto S, Dennert G. NK cells cause liver injury and facilitate the induction of $\mathrm{T}$ cell-mediated immunity to a viral liver infection. $\mathrm{J}$ Immunol 2000;164:6480-6486.

[10] Muhlen KA, Schumann J, Wittke F, Stenger S, Van Rooijen N, Van Kaer L, et al. NK cells, but not NKT cells, are involved in Pseudomonas aeruginosa exotoxin A-induced hepatotoxicity in mice. J Immunol 2004;172:3034-3041.

[11] Abe T, Kawamura H, Kawabe S, Watanabe H, Gejyo F, Abo T. Liver injury due to sequential activation of natural killer cells and natural killer T cells by carrageenan. J Hepatol 2002;36:614-623.

[12] Ochi M, Ohdan H, Mitsuta H, Onoe T, Tokita D, Hara H, et al. Liver NK cells expressing TRAIL are toxic against self hepatocytes in mice. Hepatology 2004;39:1321-1331.

[13] Dong Z, Wei H, Sun R, Hu Z, Gao B, Tian Z. Involvement of natural killer cells in Poly(I:C)-induced liver injury. J Hepatol 2004;41:966-973.

[14] Wang J, Sun R, Wei H, Dong Z, Tian Z. Pre-activation of T lymphocytes by low dose of concanavalin A aggravates toll-like receptor-3 ligand-induced $\mathrm{NK}$ cell-mediated liver injury. Int Immunopharmacol 2006;6:800-807. 
[15] Takeda K, Hayakawa Y, Van Kaer L, Matsuda H, Yagita H, Okumura K. Critical contribution of liver natural killer T cells to a murine model of hepatitis. Proc Natl Acad Sci USA 2000;97:5498-5503.

[16] Toyabe S, Seki S, Iiai T, Takeda K, Shirai K, Watanabe H, et al. Requirement of IL-4 and liver NK1+T cells for concanavalin Ainduced hepatic injury in mice. J Immunol 1997;159:1537-1542.

[17] Nakagawa R, Nagafune I, Tazunoki Y, Ehara H, Tomura H, Iijima R, et al. Mechanisms of the antimetastatic effect in the liver and of the hepatocyte injury induced by alpha-galactosylceramide in mice. J Immunol 2001;166:6578-6584.

[18] Kakimi K, Guidotti LG, Koezuka Y, Chisari FV. Natural killer T cell activation inhibits hepatitis B virus replication in vivo. J Exp Med 2000;192:921-930.

[19] Kimura K, Kakimi K, Wieland S, Guidotti LG, Chisari FV. Activated intrahepatic antigen-presenting cells inhibit hepatitis B virus replication in the liver of transgenic mice. $\mathrm{J}$ Immunol 2002;169:5188-5195.

[20] Pasquetto V, Guidotti LG, Kakimi K, Tsuji M, Chisari FV. Hostvirus interactions during malaria infection in hepatitis B virus transgenic mice. J Exp Med 2000;192:529-536.

[21] Sitia G, Iaoqawa M, Kakimi K, Wieland SF, Chisari FV, Guidotti LG. Depletion of neutrophils blocks the recruitment of antigennonspecific cells into the liver without affecting the antiviral activity of hepatitis B virus-specific cytotoxic T lymphocytes. Proc Natl Acad Sci USA 2002;99:13717-13722.

[22] Kakimi K, Lane TE, Wieland S, Asensio VC, Campbell IL, Chisari FV, et al. Blocking chemokine responsive to gamma-2/ interferon (IFN)-gamma inducible protein and monokine induced by IFN-gamma activity in vivo reduces the pathogenetic but not the antiviral potential of hepatitis B virus-specific cytotoxic $\mathrm{T}$ lymphocytes. J Exp Med 2001;194:1755-1766.

[23] Guidotti LG, Rochford R, Chung J, Shapiro M, Purcell R, Chisari FV. Viral clearance without destruction of infected cells during acute HBV infection. Science 1999;284:825-829.

[24] Yongyan Chen, Haiming Wei, Rui Sun, Zhigang Tian. Impaired function of hepatic natural killer cells from murine chronic HBsAg carriers. Int Immunopharmacol 2005;5:1839-1852.

[25] Chisari FV, Pinkert CA, Milich DR, Fillippi P, Mclachlan A, Palmiter RD, et al. A transgenic mouse model of the chronic hepatitis B surface antigen carrier state. Science 1985;230:1157-1160.

[26] Bigger JE, Thomas III CA, Atherton SS. NK cell modulation of murine cytomegalovirus retinitis. J Immunol 1998;160:5826-5831.

[27] Fukumura D, Yonei Y, Kurose I, Saito H, Ohishi T, Higuchi H, et al. Role in nitric oxide in Kupffer cell-mediated hepatoma cell cytotoxicity in vitro and ex vivo. Hepatology 1996;24:141-149.

[28] Wei Jiang, Rui Sun, Haiming Wei, Zhigang Tian. Toll-like receptor 3 ligand attenuates LPS-induced liver injury by downregulation of toll-like receptor 4 expression on macrophages. Proc Natl Acad Sci USA 2005;102:17077-17082.

[29] Jaruga B, Hong F, Kim WH, Gao B. IFN-gamma/STAT1 acts as a proinflammatory signal in $\mathrm{T}$ cell-mediated hepatitis via induction of multiple chemokines and adhesion molecules: a critical role of IRF-1. Am J Physiol Gastrointest Liver Physiol 2004;287:G1044-G1052.

[30] Trobonjaca Z, Kroger A, Stober D, Leithauser F, Moller P, Hauser $\mathrm{H}$, et al. Activating immunity in the liver. II. IFN-beta attenuates NK cell-dependent liver injury triggered by liver NKT cell activation. J Immunol 2002;168:3763-3770.

[31] Arase H, Mocarski ES, Campbell AE, Hill AB, Lanier LL. Direct recognition of cytomegalovirus by activating and inhibitory NK cell receptors. Science 2002;296:1323-1326.

[32] Smith HR, Heusel JW, Mehta IK, Kim S, Dorner BG, Naidenko $\mathrm{OV}$, et al. Recognition of a virus-encoded ligand by a natural killer cell activation receptor. Proc Natl Acad Sci USA 2002;99:8826-8831.
[33] Voigt V, Forbes CA, Tonkin JN, Degli-Esposti MA, Smith HR, Yokoyama WM, et al. Murine cytomegalovirus m157 mutation and variation leads to immune evasion of natural killer cells. Proc Natl Acad Sci USA 2003;100:13483-13488.

[34] Krmpotic A, Busch DH, Bubic I, Gebhardt F, Hengel H, Hasan M, et al. MCMV glycoprotein gp40 confers virus resistance to CD8+ T cells and NK cells in vivo. Nat Immunol 2002;3:529-535.

[35] Lodoen MB, Abenes G, Umamoto S, Houchins JP, Liu F, Lanier LL. The cytomegalovirus $\mathrm{m} 155$ gene product subverts natural killer cell antiviral protection by disruption of H60-NKG2D interactions. J Exp Med 2004;200:1075-1081.

[36] Krmpotic A, Hasan M, Loewendorf A, Saulig T, Halenius $A$, Lenac $\mathrm{T}$, et al. NK cell activation through the NKG2D ligand MULT-1 is selectively prevented by the glycoprotein encoded by mouse cytomegalovirus gene m145. J Exp Med 2005;201:211-220.

[37] Hasan M, Krmpotic A, Ruzsics Z, Bubic I, Lenac T, Halenius A, et al. Selective down-regulation of the NKG2D ligand H60 by mouse cytomegalovirus m155 glycoprotein. J Virol 2005;79:2920-2930.

[38] Lenac T, Budt M, Arapovic J, Hasan M, Zimmermann A, Simic $\mathrm{H}$, et al. The herpesviral $\mathrm{Fc}$ receptor fcr-1 down-regulates the NKG2D ligands MULT-1 and H60. J Exp Med 2006;203:1843-1850.

[39] Kusters S, Gantner F, Kunstle G, Tiegs G. Interferon gamma plays a critical role in $\mathrm{T}$ cell-dependent liver injury in mice initiated by concanavalin A. Gastroenterology 1996;111:462-471.

[40] Tagawa Y, Sekikawa K, Iwakura Y. Suppression of concanavalin A induced hepatitis in IFN-gamma(-/-) mice, but not in TNFalpha(-/-) mice: role for IFN-gamma in activating apoptosis of hepatocytes. J Immunol 1997;159:1418-1428.

[41] Car BD, Eng VM, Schnyder B, Ozmen L, Huang S, Gallay P, et al. Interferon gamma receptor deficient mice are resistant to endotoxic shock. J Exp Med 1994;179:1437-1444.

[42] Gilles PN, Guerrette DL, Ulevitch RJ, Schreiber RD, Chisari FV. HBsAg retention sensitizes the hepatocyte to injury by physiological concentrations of interferon-gamma. Hepatology 1992;16:655-663.

[43] Gao B. Cytokines, STATs and liver disease. Cell Mol Immunol 2005;2:92-100.

[44] Hong F, Jaruga B, Kim WH, Radaeva S, El-Assal ON, Tian Z, et al. Opposing roles of STAT1 and STAT3 in T cell-mediated hepatitis: regulation by SOCS. J Clin Invest 2002;110:1503-1513.

[45] Kim WH, Hong F, Radaeva S, Jaruga B, Fan S, Gao B. STAT1 plays an essential role in LPS/D-galactosamine-induced liver apoptosis and injury. Am J Physiol Gastrointest Liver Physiol 2003;285:G761-G768

[46] Siebler J, Wirtz S, Klein S, Protschka M, Blessing M, Galle PR, et al. A key pathogenic role for the STAT1/T-bet signaling pathway in T-cell-mediated liver inflammation. Hepatology 2003;38:1573-1580.

[47] Mizuhara H, O’Neill E, Seki N, Ogawa T, Kusunoki C, Otsuka $\mathrm{K}$, et al. T cell activation-associated hepatic injury: mediation by tumor necrosis factors and protection by interleukin 6. J Exp Med 1994;179:1529-1537.

[48] Ksontini R, Colagiovanni DB, Josephs MD, Edwards 3rd CK, Tannahill CL, Solorzano CC, et al. Disparate roles for TNFalpha and Fas ligand in concanavalin A-induced hepatitis. J Immunol 1998;160:4082-4089.

[49] Verdijk RM, Mutis T, Esendam B, Kamp J, Melief CJ, Brand A, et al. Polyriboinosinic polyribocytidylic acid (poly(I:C)) induces stable maturation of functionally active human dendritic cells. $\mathbf{J}$ Immunol 1999;163:57-61

[50] Fogler WE, Volker K, Watanabe M, Wigginton JM, Roessler P, Brunda MJ, et al. Recruitment of hepatic NK cells by IL-12 is dependent on IFN-gamma and VCAM-1 and is rapidly down- 
regulated by a mechanism involving $\mathrm{T}$ cells and expression of Fas. J Immunol 1998;161:6014-6021.

[51] Nicoletti F, Di Marco R, Zaccone P, Salvaggio A, Magro G, Bendtzen $\mathrm{K}$, et al. Murine concanavalin A-induced hepatitis is prevented by interleukin 12 (IL-12) antibody and exacerbated by exogenous IL-12 through an interferon-gamma-dependent mechanism. Hepatology 2000;32:728-733.
[52] Zheng BJ, Ng MH, He LF, Yao X, Chan KW, Yuen KY, et al. Therapeutic efficacy of hepatitis B surface antigen-antibodiesrecombinant DNA composite in HBsAg transgenic mice. Vaccine 2001;19:4219-4225.

[53] Perrillo RP. Acute flares in chronic hepatitis B: the natural and unnatural history of an immunologically mediated disease. Gastroenterology 2000;120:1009-1022. 